\title{
Design and Implementation of English Learning System Based on Computer Network Platform
}

\author{
https://doi.org/10.3991/ijet.v12.i08.7139 \\ $\mathrm{Hu} \mathrm{Gao}^{(\varpi)}$, Yanbin Ma \\ Langfang Teachers University, Langfang, China, \\ 1465263517 @qq. com \\ Peng Geng \\ Shijiazhuang Tiedao University, Shijiazhuang, China
}

\begin{abstract}
With the popularity of English across the world, demands grow for English of daily use. By reviewing the English learning methods and its patterns at home and abroad, this paper conducted a major analysis on the status of English self-learning in China. On this basis, a computer network platform based English learning system was designed and realized by using software engineering approaches, whose development techniques are discussed subsequently. Finally, the performance and safety of the online English learning platform are tested. The test results show that the system is effective in improving students' ability to learn English by themselves.
\end{abstract}

Keywords - English learning, object-oriented development, computer network, system design.

\section{$1 \quad$ Introduction}

China has the world's largest number of English learner, but most of them think it difficult to learn English. Related studies show that the difficulty is mainly related to two factors, i.e. learning motivation and learning methods. According to the survey results of college students' English learning motivation, there are three types of initiatives: 1. Test-oriented learning, preparing for the College English Test Band 4 and Band 6; 2. Career-oriented learning, arising from social requirements as English is helpful to finding satisfactory jobs; this type has the largest proportion among the three types [1-3]; 3. Aimless learning, mostly driven by hobbies and interests. The survey findings also indicate that the effect of hobby-driven English learning is the best. Instead of in-depth understanding and practical application, a large majority of English studiers adopt the incorrect learning methods such as rote learning of words and grammars. As a result, they fail to achieve good learning effect or high efficiency [4].

Other related research shows that the current college English learners lack high self-learning ability, effective learning skills and methods, as well as clear targets. In addition, their English learning outcomes cannot be appropriately supported by self- 
exercise or self-examination. As a comparison, in the traditional learning mode, students play the role of passive acceptors of knowledge, information, and learning effect tests. Few of the effect tests are organized and performed by themselves [5-6] in a way that revealing self-learning problems and strengthening the practice of week points. Therefore, it is necessary to design an English learning system to provide them with such a test environment. At present, the network computer technology has found widespread application in the field of English education. These accessible advanced techniques are conducive to students' cultivating independent learning capability and improving self-learning effects. This paper mainly analyzes the current requirements of English learning for college students, and designs a set of relevant English autonomous learning platform, with its functions being achieved [7-9].

\section{The key technologies of secondary development based on computer network platforms}

\subsection{Ubuntu}

In order to meet the corresponding stability requirements and to reduce development costs, we prefer the Ubuntu operating system to design our network learning system. The reason is that Unix system only provides paid service albeit wellperformed, and Windows system tends to perform much poorly once it allots insufficient RAM. Linux operating system is characterized by strong adaptability, wide usage, reliable memory allotment and high stability. After these comprehensive considerations, we choose Ubuntu operating system [10].

\subsection{Apache2}

Apache is a frequently-used server software in the system development field, occupying a far larger market share than Microsoft IIS [11]. Compared to a variety of Web server software, Apache has obvious advantages such as the simple and easy-touse property, fast speed, stable performance, and high compatibility with operating system. The uncomplicated software configuration allows Apache to be accessible to new developers. This software can be installed in two ways: source code installation and binary package installation, which have various merits, demerits and application scopes. Users of different levels can choose from them according to their own needs. In light of the Ubuntu system used in the paper, we install Apache with binary packages. In this case, the installation package can be downloaded and launched directly on our order, and Apache 2 can be launched immediately or stop running at command in the well-installed software system [12]. With the apache2.conf file in the installation package directory, one can modify and set the server, such as redirecting 80 port to other non-conflicting ports by setting the port command. The function of server setting is generally required in establishing sites, as it facilitates multi-site management. In default setting, files sent from this server are usually located in the / var / www directory, but the installation site is modifiable. 


\subsection{PHP5}

PHP, known as a generic open-source scripting language, is easy to learn for developers of $\mathrm{C}$ language, Java and Perl due to the large amount of their grammatical similarities. At present, its highly-frequent application in the field of Web development provides great convenience to web developers. Some programmers even install PHP in some large websites.

Due to its effective operation and much lower consumption amount of system resources than CGI in running dynamic webpages, PHP can be embedded into HTML document to improve the running efficiency of webpages to a large extent [13-16]. PHP-based programs are endowed with a high degree of cross-platform property, and thus can conveniently run in all kinds of databases and their operating systems. In addition, PHP can be combined easily with Limux, Apache and other software systems with no risks of incompatibility. Therefore, it is of great advantage in developing our system [17-20].

\section{The encoding and realization of English self-learning platform}

\subsection{The flow chart of system overall functions}

This flow chart is mainly used to describe the realization of system functions, so as to lay the foundation for subsequent work. Therefore, it is frequently used in the field of system development. It displays the process of user identity identification and system response. Details of the flow chart is shown in Figure 1.

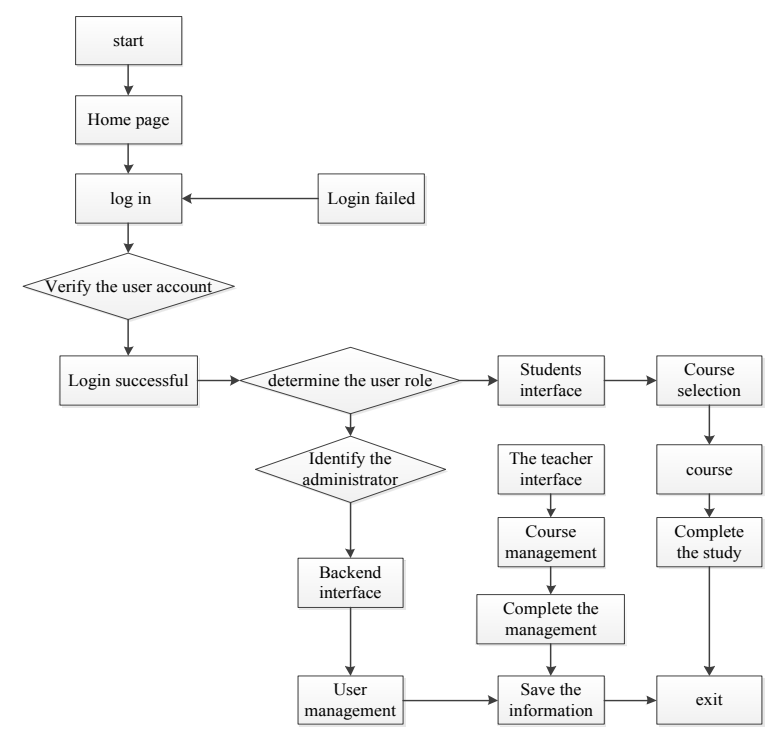

Fig. 1. The flow chart of system overall function 


\subsection{The realization of system public module}

In developing the system, we set log-in module, log-out module and other public modules to achieve its function. The log-in module is taken as an example to expound the complicate realization of module functions. The system will first verify user access through the log-in module, and then set limits on log-in time. Users without any operation during the predefined log-in time are required to return to the log-in page to re-verify accounts and passwords. It simultaneously maintains the confidentiality of user ID and spares the efforts for users to perform ID identification for several times. After users are authenticated, the system will jump to the personal page. Figure 2 shows the details of the log-in process, and Figure 3 is the corresponding log-in interface.

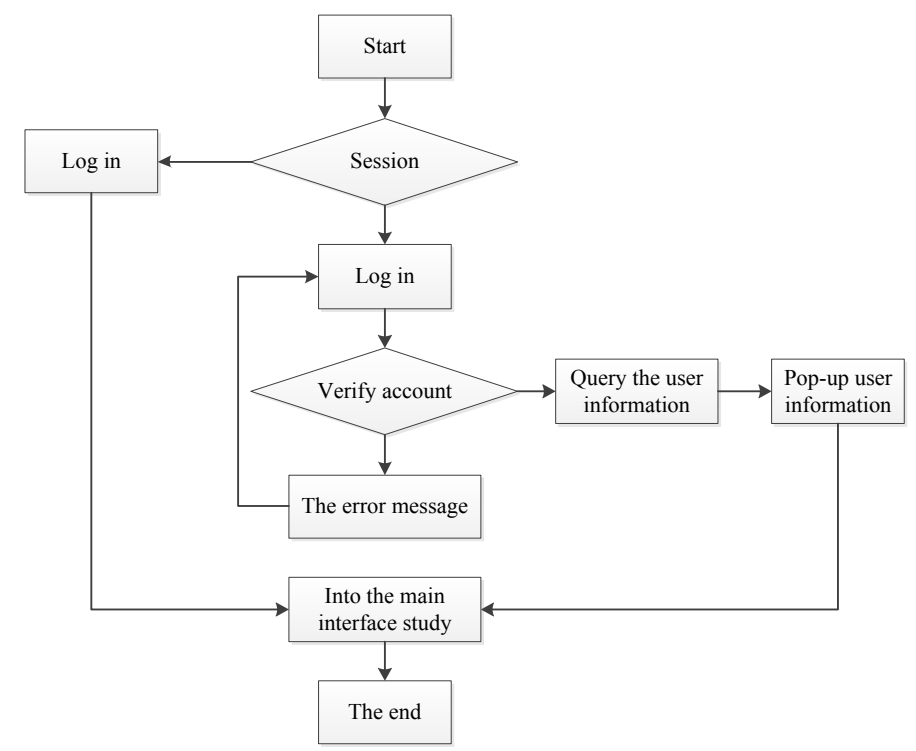

Fig. 2. The flow chart of online English learning platforms
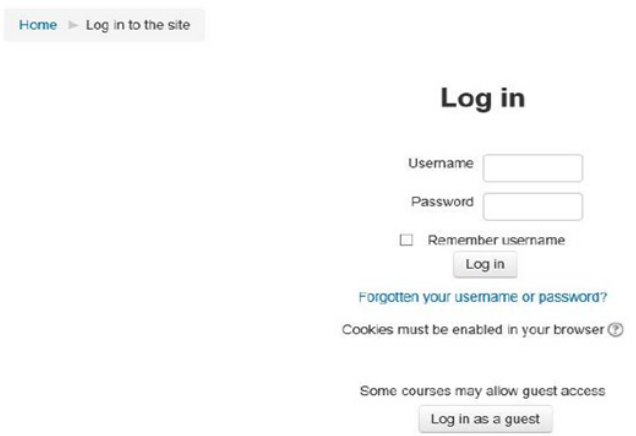

Fig. 3. The main interface of user $\log$ in 


\subsection{Course content management}

In order to facilitate curriculum management, we unified the system pattern so that all teachers can manage the system without accepting tailor-made training. Course management should be designed to simplify operations and to render the curriculum management more accessible to teachers. For instance, we may add or edit system documents with Microsoft Word operations; we can also categorize English skills according to course materials. This management mainly involves skills of reading, listening and writing, such as separating listening practice from middle-length-to-long reading material practice and writing training. The corresponding functional process is shown in Figure 4, and the interface is displayed in Figure 5.

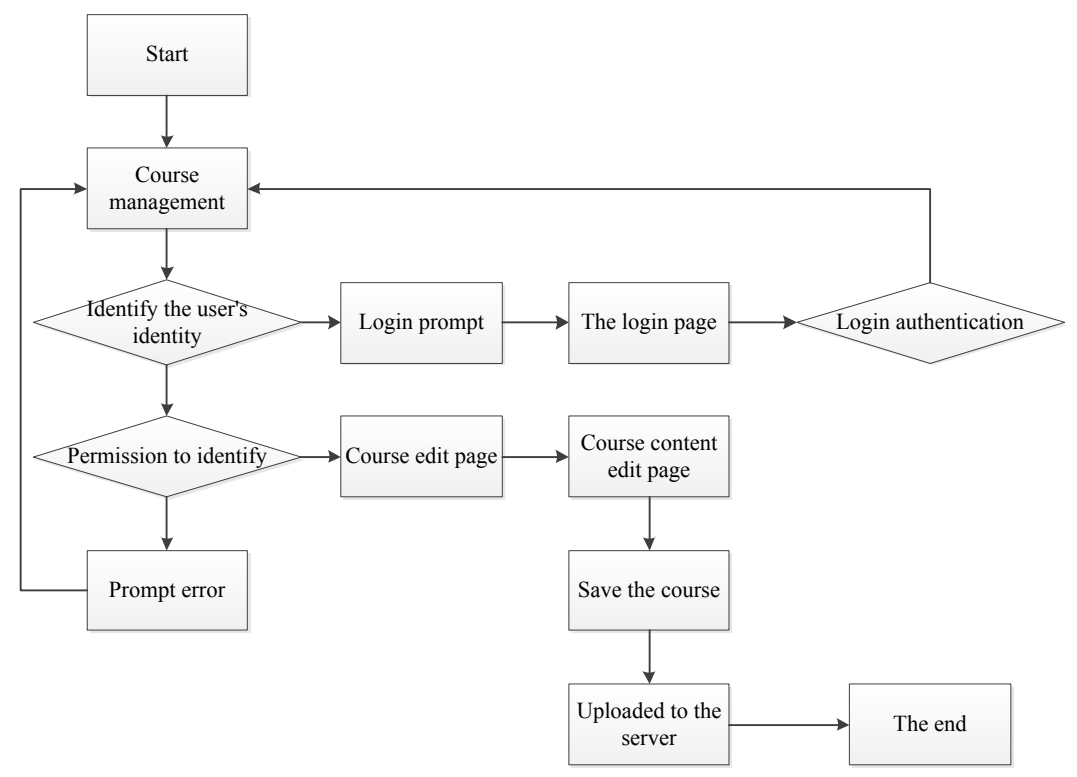

Fig. 4. The flow chart of course content management

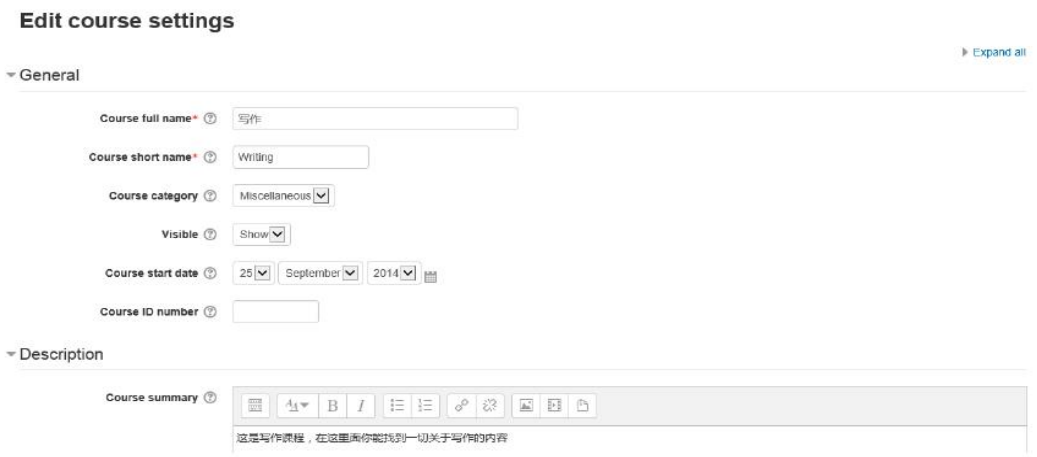

Fig. 5. The interface of course management function 
In managing course on the Moodle platform, we set no limits on the online learning duration and online time management. Instead, we add some new functions to satisfy the special needs of freshmen. There are quite a great number of factors to consider in running special sentences by the script language of PHP, such as online timekeeping. Therefore, we insert the log-out time into the database and determine the log-in duration by comparing log-in time with log-out time. In addition, we check the session status through scripts, so as to time the duration more accurately.

\subsection{User management}

As one of the main system functions, user management refers to the management of teacher users and student users by administrators who have special rights on applications. In order to meet the corresponding management requirements, the function module should achieve the following several functions: 1 . Personal information management, including management on individual users' information, rights, classes, etc. 2. Bulk user management, which helps achieve efficient and centralized management in the case of a massive number of users. This function can improve management efficiency, avoid manual misoperation, and reduce repetitive management operations. Figure 6 and Figure 7 are the details of the management function interface.

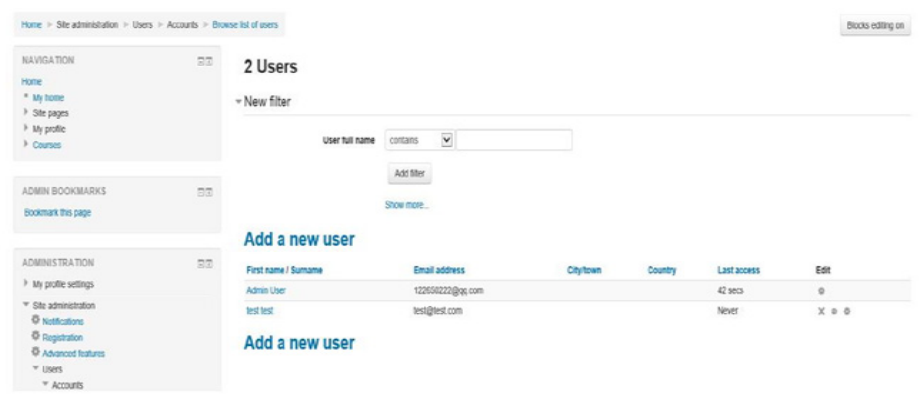

Fig. 6. User management

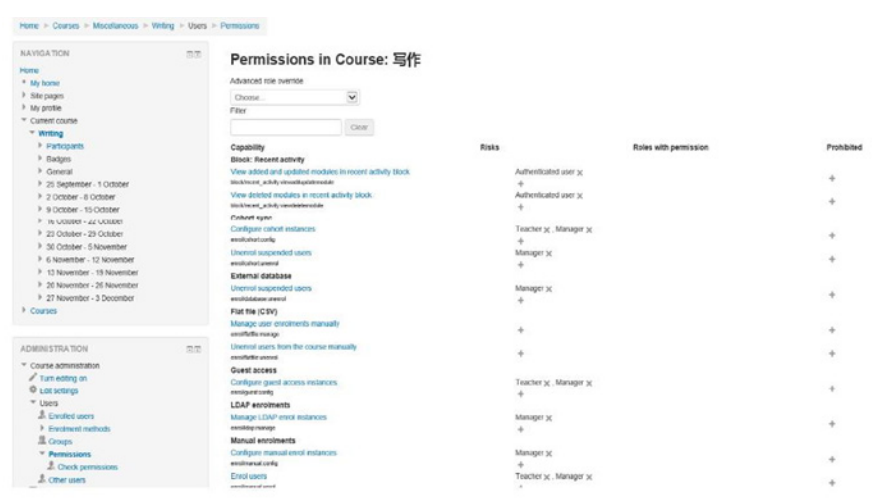

Fig. 7. User rights management 


\section{System test}

\subsection{Security test}

Through the above design, we have realized the functions of different system modules. To verify the feasibility of system functions, it is necessary to test the system from different aspects. In light of the performance requirements of system functions, we conducted the respective security test and performance test on the system. Below are the test details. As a popular performance test, security test is largely used to test the software response to unauthorized or malicious activities, aimed at preventing system data from data loss. Among the massive security test items, we let authorized users and unauthorized users perform respective permitted operations and unpermitted operations and check the corresponding system responses. This is a method for us to verify whether the system can identify users of different identities and whether the system limits user operations within the extent of authority.

After the completion of basic functional tests and troubleshooting, we should test some of the frequently-seen security loopholes. This test is relatively simple. We first let users of different levels operate in corresponding function modules. Then, we examine and record the system's response to advanced permissions obtained by browser injection. By observing and recording system response, we calculate whether there are security vulnerabilities in the system. The result of the system security test is listed in Table 1.

Table 1. Security test results

\begin{tabular}{|c|l|l|}
\hline Number & \multicolumn{1}{|c|}{ Test content } & \multicolumn{1}{c|}{ Test result } \\
\hline 1 & Wrong choice function & Cannot be used \\
\hline 2 & Via the URL into the content & Login prompt \\
\hline 3 & Injection vulnerabilities & Unable to inject \\
\hline
\end{tabular}

\subsection{Function test results}

The main purpose of this platform is to provide a convenient way for students to learn English by themselves with their learning effect being tested. What is more, as we intend to expand the number of student users, the system is designed to hold a large number of target users, which requires the system to undertake the concurrent response ability test and stability test.

Multi-user concurrent test is to test the system's ability to provide service to massive users. The test content can be divided into load test and pressure test. By continuing to enlarge the user volume, we observe the system response until the system can no more operate normally. The major performance index of the system is the multiuser concurrent performance at the normal status and at the ultimate state, respectively.

Purpose: To test the system performance when two hundred users concurrently access the system. 
Methods: Concurrent access is realized by apache bench virtual users. In this case, the average time of system response and bandwidth conditions are recorded in the data format for analysis. The analysis result is shown in Table 2.

Table 2. Concurrency test results

\begin{tabular}{|c|c|c|c|c|}
\hline Number of concurrent clients & 10 & 50 & 100 & 200 \\
\hline The average response time & $0.036(\mathrm{~s})$ & $0.814(\mathrm{~s})$ & $2.154(\mathrm{~s})$ & $5.123(\mathrm{~s})$ \\
\hline Refuse service rate & $0 \%$ & $0 \%$ & $1.3 \%$ & $2.5 \%$ \\
\hline
\end{tabular}

\section{Conclusion}

By analyzing the current situation and demands of English self-learning of Chinese college students, we mainly develop an English self-learning system and its function modules and structures in this paper. Then, the properties and functions of the system are tested by using some software. The test results show that the system is of good performance. Its functions have satisfied the development requirements, playing certain roles in English self-learning practice.

\section{References}

[1] Chen, C. M., Chung, C. J. (2008). Personalized mobile english vocabulary learning system based on item response theory and learning memory cycle. comput educ. Computers \& Education, 51(2), 624-645. https://doi.org/10.1016/j.compedu.2007.06.011

[2] Huang, Y. M., Huang, Y. M., Huang, S. H., Lin, Y. T. (2012). A ubiquitous english vocabulary learning system: evidence of active/passive attitudes vs. usefulness/ease-of-use. Computers \& Education, 58(1), 273-282. https://doi.org/10.1016/j.compedu.2011.08.008

[3] Hsu, M. H. (2008). A personalized english learning recommender system for esl students. Expert Systems with Applications, 34(1), 683-688. https://doi.org/10.1016/j.eswa. 2006.10.004

[4] Roberts, J. A., Moradi, H., Grzymala-Busse, J. W. (1998). Entropy of english text: experiments with humans and a machine learning system based on rough sets. Information Sciences, 104(1), 31-47.

[5] Huang, Y. M., Huang, Y. M., Huang, S. H., Lin, Y. T. (2012). Huang, y.-m. et al.: a ubiquitous english vocabulary learning system: evidence of active/passive attitudes vs. usefulness/ease-of-use. computers \& education 58(1), 273-282. Computers \& Education, 58(1), 273-282. https://doi.org/10.1016/j.compedu.2011.08.008

[6] Anaraki, F. B. (2008). Development of a flash-based mobile learning system for english as second language. British Journal of Pharmacology, 75(2), 409-414.

[7] Wang, Y. H. (2014). Developing and evaluating an adaptive business english self-learning system for efl vocabulary learning. Mathematical Problems in Engineering, 2014(2), 1-7. https://doi.org/10.1155/2014/972184

[8] Sun, C. Y., Chang, K. Y. (2016). Design and development of a location-based mobile learning system to facilitate english learning. Universal Access in the Information Society, 15(3), 1-13. https://doi.org/10.1007/s10209-014-0392-x 
[9] Hasegawa, T., Koshino, M., Ban, H. (2015). An english vocabulary learning support system for the learner's sustainable motivation. SpringerPlus, 4(1), 99. https://doi.org/10.1186/s40064-015-0792-2

[10] Yalin, Liao. (2013). Design and study of computer aided english learning system. International Journal of Technology Management, 11, 53-56.

[11] Qingli, Zhao. (2013). Design and application of english learning system based on b/s structure. International Journal of Technology Management, 7, 97-99.

[12] Kawakami, T. (1981). Optional learning system in college english. International Journal of Pediatric Otorhinolaryngology, 3.

[13] Yoshii, R. (2014). Itsleadr: intelligent tutoring system for learning english articles. American Journal of Hematology, 47(1), 66-66.

[14] Cumming, G., Sussex, R., Cropp, S. (1993). Learning english as a second language: towards the "mayday" intelligent educational system. Computers \& Education, 20(1), 119126. https://doi.org/10.1016/0360-1315(93)90078-W

[15] Jia, J., Chen, Y., Ding, Z., Ruan, M. (2012). Effects of a vocabulary acquisition and assessment system on students' performance in a blended learning class for english subject. Computers \& Education, 58(1), 63-76. https://doi.org/10.1016/j.compedu.2011.08.002

[16] Song, P. (2015). A learning approach to english online video teaching system design and implementation. Geological Journal, 51(5), 737-747. https://doi.org/10.2991/etmhs15.2015 .104

[17] Yang, N. D. (2006). Developing a web-based learning portfolio system for english teaching and assessment. IEEE Transactions on Power Delivery, 7:2(2), 729-734.

[18] Cutrim, E. S. (2008). Using a voting system in conjunction with interactive whiteboard technology to enhance learning in the english language classroom. Computers \& Education, 50(1), 338-356. https://doi.org/10.1016/j.compedu.2006.07.001

[19] Liu, G. Z., Lo, H. Y., Wang, H. C. (2013). Design and usability testing of a learning and plagiarism avoidance tutorial system for paraphrasing and citing in english: a case study. Computers \& Education, 69(4), 1-14. https://doi.org/10.1016/j.compedu.2013.06.011

[20] David, B., Melita, G. (2010). Moodle - the implementation of a course management system/virtual learning environment in a freshman english program. Bmc Pediatrics, 10(1), 111.

\section{$7 \quad$ Authors}

Hu Gao (corresponding author) is a lecturer in Langfang Teachers University, mainly engaged in Information Technology, Curriculum Integration and Digital Media Technology.

Yanbin Ma is a lecturer in Langfang Teachers University, mainly engaged in Teaching Design and Digital Media Technology.

Peng Geng is an associate professor at the School of information science and technology, Shijiazhuang Tiedao University, Shijiazhuang, China, mainly engaged in Design and Development of Educational Resources.

Article submitted 12 May 2017. Published as resubmitted by the authors 17 June 2017. 